\title{
INVESTIGATION OF PRESSURE REGULATOR REPLACEMENT BY TURBO EXPANDER IN HUNGARIAN GAS TRANSFER STATIONS
}

\author{
Anna Bella Galyas \\ University of Miskolc, Miskolc - Egyetemváros, Miskolc, Hungary, gazgab@uni-miskolc.hu \\ László Tihanyi \\ University of Miskolc, Miskolc - Egyetemváros, Miskolc, Hungary, tihanyil@kfgi.uni-miskolc.hu \\ István Szunyog \\ University of Miskolc, Miskolc - Egyetemváros, Miskolc, Hungary, szunyogi@ kfgi.uni-miskolc.hu \\ László Kis \\ University of Miskolc, Miskolc - Egyetemváros, Miskolc, Hungary, oljkisl@ uni-miskolc.hu
}

Keywords: turbo expander, transmission system, energy efficiency, natural gas, power production

Abstract: The "Strategy for a stable and adaptable energy union and a forward-looking climate policy", developed by the European Commission and endorsed in 2015, states that "... our goal is to make the energy union a long-term sustainable carbon-free and climate-friendly economy" [1]. As a result of the above, we have been looking for the conditions and the technical solutions under which the necessary pressure regulation at the gas transfer stations can use the pressure energy economically.

\section{Introduction}

One of the tasks of the gas transfer stations is that the pressure regulators installed therein have to reduce the pressure of the natural gas from the high pressure transmission system and to supply them to the consumers or to the gas distribution system at the pressure defined in the "Business and Commercial Code of the Hungarian Natural Gas System" (hereinafter referred to as ÜKSZ). During the process, there is a high level of energy loss that is lost without recovery in conventional pressure regulating systems. It has been known for a long time that natural gas pressure can be utilized using a turbo expander and an attached electric generator. The electricity thus produced can, among other things, be used to reduce the energy demand of the gas transfer stations or to be supplied into the electric network.

In this paper, the energy requirement by conventional pressure regulators and turbo expanders are presented along with the amount of energy produced by the latter. The Aspen HYSYS technological design software used in the oil and gas industry was used for carrying out the required investigations.

\section{Infrastructure of the Gas Supply System in Hungary}

Natural gas plays a significant role in the energy supply of Hungary, and its delivery to users is carried out in the natural gas supply system. All mentioned pressures are overpressures.

The natural gas transmission system operated by the FGSZ LTD. consists of supply points "0", compressor stations, gas hubs, metering stations, high pressure pipelines and gas transfer stations that are directly connected to regional gas supply companies and to industrial customers. The natural gas transmission system is the central element of pipeline energy supply that delivers natural gas from the production fields, from imports or from underground gas storages to consumer districts. In addition, it ensures the technical conditions for accurate measurement and settlement in the country's legislation. The natural gas pipelines operate in a pressure range of 25-100 bar, allowing them to safely and economically transport natural gas [2]. The Hungarian natural gas transmission system has a typical diameter of 100 to $1400 \mathrm{~mm}$ and an operating pressure of 25 to $75 \mathrm{bar}$. The endpoint of the high-pressure gas transmission system is the gas transfer station to which a smaller distribution network is connected. At these border points, controlled gas transmission to the connected system operators and direct industrial users is continuously maintained. Distribution system operators are supplying natural gas to nearly 3.5 million consumers via gas distribution networks operating at less than 25 bar. The Hungarian national regulations defines a high-medium (25>p $>10$ bar), medium $(10>p>0.1$ bar) and low ( $<<0.1$ bar) pressure range as the operating range of gas distribution systems. In Hungary, apart from some exceptions, to the endpoints of the gas transmission systems 6 bar gas distribution systems are connected [3].

At the gas transfer station, which is the connection between the gas transmission system and gas distribution system, the regulations on the physical parameters of natural gas have to satisfy the provisions of ÜKSZ. According to the regulations, the gas temperature measured at the exit points has to be above $0{ }^{\circ} \mathrm{C}$. For the nominal exit pressure value, a range of 3 to $15 \mathrm{bar}$ is specified for new 
exit points, for existing exit points the pressure can be adjusted according to the system suitability test [4]. In the

\section{Presentation of the Gas Transfer Station}

The gas transfer station is the endpoint of the natural gas transmission system, a technological station connected to the end of a transmission line or a branch line therefrom, whereby the delivered gas is transmitted to the industrial consumer or to the gas supply system. At present, there are nearly 400 gas transfer stations on the domestic gas transmission system, with the main tasks of filtration, gas heating, pressure regulation, pressure assurance, gas quantity measurement and proper odor setting [2].

The stations have two full, uniform, disconnectable, parallel pressure regulating branches; their default configuration is filter, heat exchanger, shut-in valve, monitor regulator, active regulator, low capacity (defect gas) relief valve with measurement device. The most important element of the installation is the pressure regulator coupled with the shut-in valve. The pressure regulator maintains the flow from the gas transport system to a lower pressure line, while the pressure of the lower pressure side is kept constant even at varying inlet pressure. The currently commercially available pressure regulators are pneumatic equipment whose working fluid is natural gas. The shut-in valve is the ultimate tool for limiting overpressure. The filter unit is in front of the pressure regulator, the odor unit is located after the pressure regulator. On the low pressure side of the station there is the measuring unit and the spare odor unit. Preheating natural gas is necessary to avoid hydrate formation when the pressure drop exceeds 14 bar. The natural gas is heated majority of the gas transfer stations, the transfer of the natural gas supplied is 6 bar for the distribution system.

by a counter-current tubular heat exchanger to which the hot water is provided by gas boilers in separate premises. In this system, the heat input is directly in front of the pressure regulator, so the heat loss is minimal and the gas flow temperature can be precisely controlled. Shut-in valves are pressure controlled closing elements that can be used to disable gas flow immediately. The shut-in valve is installed in front of the pressure regulator but is controlled by the pressure after the regulator. Controlled pressure acts through the impulse line with small diameter to the pneumatic control unit which changes the flow cross section by changing the pressure of the working medium. [2].

\section{Placing the turbo expander in pressure reduction station}

\subsection{Presentation of turbo expander}

A turbo expander, also known as expansion turbine, is a radial or axial turbine through which energy can be produced using the expansion of high pressure gas. Both the radial and axial turbines are used in practice, although the use of the former is more common. The turbo expander and the generator are connected to each other on a common axis.

The so-called cold energy extracted from natural gas is transformed into mechanical energy that drives the shaft. The turbo expander is placed on the bypass line at the gas transfer station, along with a traditional pressure regulator, as shown in Figure 1.

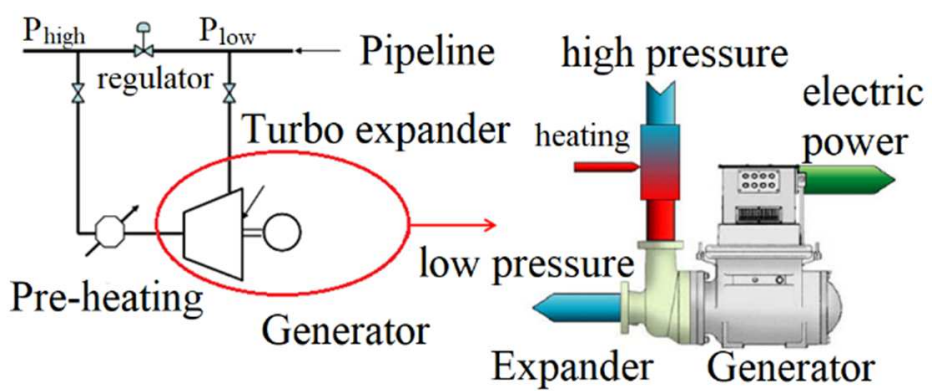

Figure 1 Schematic construction of gas transfer station with turbo expander [5, 6]

Figure 1 shows the placement and schematic operation of a turbo-expander unit. The high pressure gas needs preheating due to the high temperature drop due to the isentropic expansion. The gas enters the expander where it expands. Most of the cold energy extracted from this process is transformed into mechanical energy. The generator converts mechanical energy into electrical energy.

\subsection{Different methods of pressure regulation}

At the gas transfer station, the pressure of natural gas is reduced by pressure control valves to the desired value. In this case, it is an isenthalpic process; the enthalpy of the gas stream is identical on both sides of the valve. This throttle condition is thermodynamically irreversible. As a result of the isenthalpic throttle, the gas temperature drops due to the Joule-Thompson effect.

Contrary to the foregoing, the process using a turbo expander is isentropic, meaning that the entropy of the system is constant. In the latter case, the enthalpy change can be used for work.

The turbo expander is essentially an inverted compressor. The arrangement is capable of utilizing the 
Anna Bella Galyas; László Tihanyi; István Szunyog; László Kis

internal energy of the natural gas stream during the expansion of natural gas.

The mechanical energy extracted from natural gas results in a higher thermal drop during the isentropic process than in the case of isenthalpic throttle at the same pressure ratio. The difference between the two processes is illustrated in Figure 2.

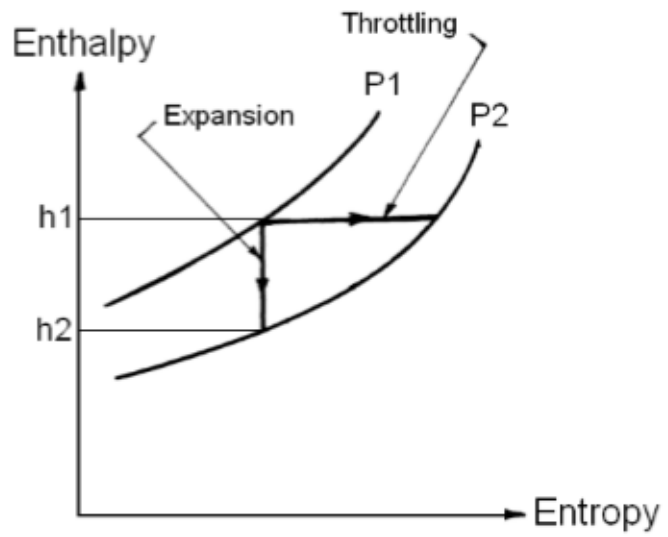

Figure 2 The difference between pressure reduction processes [7]

In the case of throttling or working expansion, the gas outlet temperature also depends on the composition of natural gas. In both cases, the high pressure gas requires preheating, but its rate is much higher when using a turbo expander than using a pressure regulator.

According to the literature, more and more publications have recently been published investigating energy usage of the gas stream at gas transfer stations [5] ... [15]. The reason for this is probably that today there are already available turbo expanders that are widely used in gas processing and gas liquefaction technologies as well as waste heat utilization cycles. In connection with the applications, not the feasibility but the economy became the focus of attention. For gas transfer stations, economics is fundamentally influenced by the fact that the use of natural gas and, as a result, the amount of the regulated gas significantly fluctuates seasonally.

\section{Investigations using simulation}

\subsection{Introduction of model used in investigation}

The results obtained from the simulation of created models using Aspen HYSYS simulation software that is used in the petroleum and gas industry are presented and evaluated in this chapter. For the comparability of the tests, we used a model that simultaneously models the state change using pressure regulator and turbo expander system with various gas flows, input pressures and input temperatures. In the model, the gas flow is distributed evenly. Thus, the calculations were performed simultaneously for both branches. The purpose of these model examinations was to determine whether the natural gas pressure energy can be utilized with the help of a turbo expander for electricity generation. The role of the gas transfer station cannot change even using a new technological solution. At gas transfer stations, natural gas shall be regulated from the current pressure and temperature values to the 6 bar discharge pressure set in ÜKSZ and the temperature of the natural gas should not be less than $0{ }^{\circ} \mathrm{C}$ after regulation.

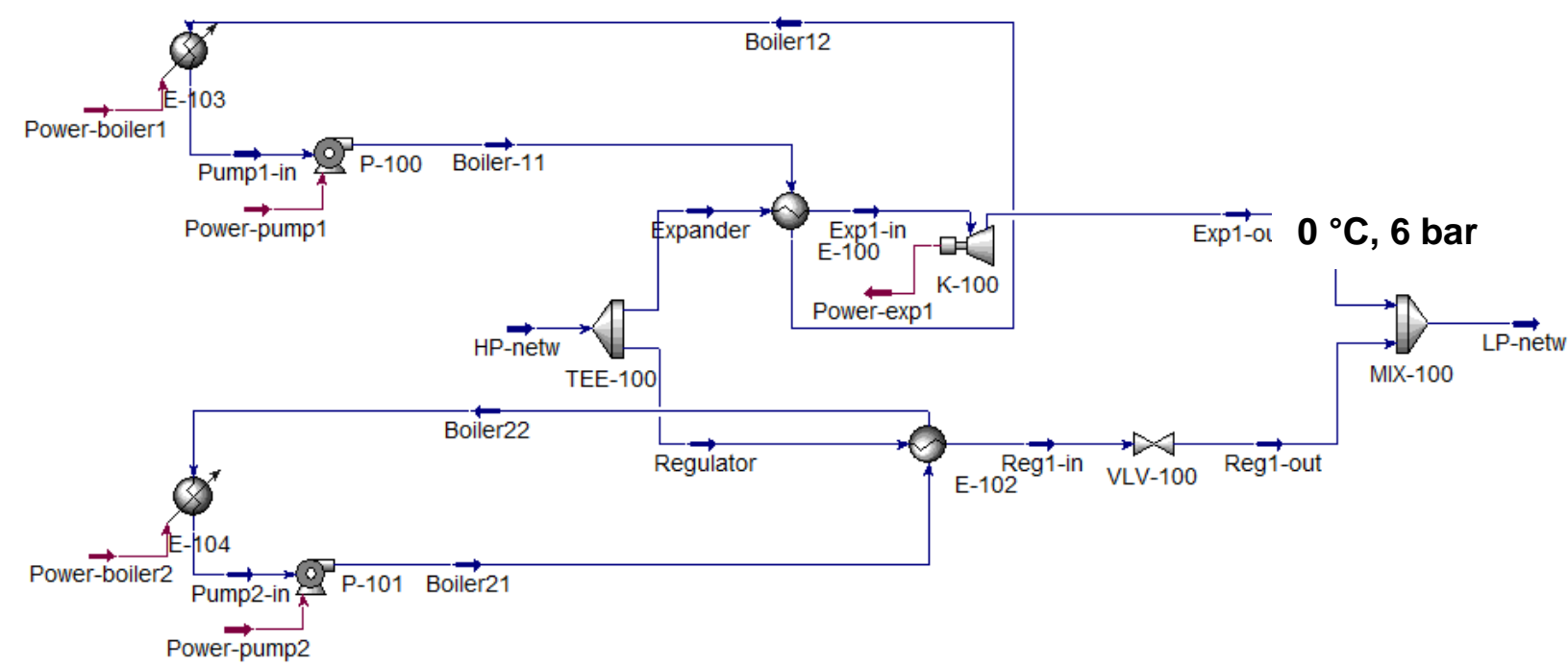

Figure 3 Aspen HYSYS model for a gas transfer station equipped with a turbo expander (upper) and a pressure regulator (lower)

In Figure 3 a branch with a turbo expander unit (top) and a branch with a conventional pressure regulator (bottom) is presented. The gas flow is the same in both branches as well as the inlet pressure and temperature at the HP-netw node and the outlet pressure and temperature in the LP-netw node. 
Anna Bella Galyas; László Tihanyi; István Szunyog; László Kis

It must be taken into account that during the winter season the amount of natural gas flowing through the gas transfer station will increase considerably and that the soil temperature will be lower than the summer temperature. Because of the above, the gas must be heated before the pressure regulation. This is done by a gas heating system in which a gas-fired boiler heats the water used as the intermediate medium to such an extent that the temperature at the output side of the pressure regulating element is at a given value. In this auxiliary system, the energy required to circulate the water is provided by an electric motor driven pump.

The pump can only operate with $100 \%$ fluid phase, so the pressure of the heating circuit must be chosen so that the heating medium remains in liquid state from the discharge side of the pump to the suction side of the pump. In some cases, especially in the case of gas transfer stations - not too far from the outlet point of the compressor stations - there may be a situation in which, regulating at 6 bar at the gas transfer station, the output temperature of 0 ${ }^{\circ} \mathrm{C}$ can only be obtained if the gas is heated up to $100{ }^{\circ} \mathrm{C}$ before the pressure regulator, occasionally exceeding this temperature. Especially when using a turbo expander, this may occur.

\subsection{Analysis of Turbo Expander and Pressure Regulating Unit}

During the tests, gas transfer stations with different capacities were tested. In order to investigate the widest range of operations, three different gas transfer station groups were defined, depending on the gas flow rate and the arrival pressure. The tests, assuming a constant typical composition of natural gas were performed at different inlet natural gas temperatures of $4{ }^{\circ} \mathrm{C}, 8{ }^{\circ} \mathrm{C}$ and $12{ }^{\circ} \mathrm{C}$.

\subsubsection{Examination of High Capacity, High-Pressure Gas Transfer Station}

High-capacity gas transfer stations were considered that are close to the compressor station and for which both the arriving pressure and the gas flow were high.

The test range of the flow rate was between 10,000 and $22,000 \mathrm{~m}^{3} / \mathrm{h}$ using $4,000 \mathrm{~m}^{3} / \mathrm{h}$ step size. A significant proportion of domestic gas transfer stations are included in this group regarding the maximum capacity. The inlet pressure was characterized by a pressure range of 45 to 55 bar. The calculation results for this category are shown in Table 1 and 2. In the tables, the energy data calculated for the natural gas pre-heating circuit, the gas heating boiler and the pump are shown. The operation of these technological units is associated with their energy usage, which should be indicated in the energy balance. In the tables, the total power requirement is shown for both cases. The value shown in the table with dark gray is the amount of energy produced by the turbo expander unit.

It is important to emphasize that the energy demand of a built-in gas heating boiler as part of the preheating circuit is covered by using natural gas for technological purposes and only the electricity needed to operate the pumps must be purchased from an external service provider.

Table 1 shows the results of a high-capacity gas transfer station with an inlet pressure of 45 bar.

\begin{tabular}{|c|c|c|c|c|c|c|c|c|c|}
\hline \multirow{2}{*}{$\begin{array}{l}p=45 \mathrm{bar} \\
T=4^{\circ} \mathrm{C}\end{array}$} & \multirow[t]{2}{*}{ Unit } & \multicolumn{2}{|c|}{$\mathrm{Q}=10,000 \mathrm{~m}^{3} / \mathrm{h}$} & \multicolumn{2}{|c|}{$Q=14,000 \mathrm{~m}^{3} / \mathrm{h}$} & \multicolumn{2}{|c|}{$\mathrm{Q}=18,000 \mathrm{~m}^{3} / \mathrm{h}$} & \multicolumn{2}{|c|}{$\mathrm{Q}=22,000 \mathrm{~m}^{3} / \mathrm{h}$} \\
\hline & & Exp. & Valve & Exp. & Valve & Exp. & Valve & Exp. & Valve \\
\hline Heating power & $\mathrm{kW}$ & 519,0 & 87,0 & 727,0 & 121,0 & 935,0 & 156,0 & 1143,0 & 191,0 \\
\hline Pump power & $\mathrm{kW}$ & 0,48 & 0,15 & 0,54 & 0,15 & 0,57 & 0,19 & 0,70 & 0,19 \\
\hline Total pon & $\mathrm{kW}$ & 519,48 & 87,15 & 727,54 & 121,15 & 935,57 & 156,19 & 1143,70 & 191,19 \\
\hline Produced & $\mathrm{kW}$ & 433,0 & 0,0 & 607,0 & & 780,0 & 0,0 & 953,0 & 0,0 \\
\hline $\mathrm{T}=8^{\circ} \mathrm{C}$ & & Exp. & Valve & Exp. & Valve & Exp. & Valve & Exp. & $\overline{\text { Valve }}$ \\
\hline Heating power & $\mathrm{kW}$ & 499,0 & 66,0 & 699,0 & 93,0 & 898,0 & 120,0 & 1099,0 & 146,0 \\
\hline Pump po & $\mathrm{kW}$ & 0,49 & 0,15 & 0,53 & 0,15 & 0,58 & 0,19 & 0,70 & 0,19 \\
\hline Total power requirement & $\mathrm{kW}$ & 499,49 & 66,15 & 699,53 & 93,15 & 898,58 & 120,19 & 1099,70 & 146,19 \\
\hline Produced energy & $\mathrm{kW}$ & 433,0 & 0,0 & 607,0 & 0,0 & 780,0 & 0,0 & 953,0 & 0,0 \\
\hline $\mathrm{T}=12^{\circ} \mathrm{C}$ & & Exp. & Valve & Exp. & Valve & Exp. & Valve & Exp. & Valve \\
\hline Heating power & $\mathrm{kW}$ & 479,0 & 46,0 & 670,0 & 93,0 & 862,0 & 84,0 & 1054,0 & 102,0 \\
\hline Pump power & $\mathrm{kW}$ & 0,49 & 0,15 & 0,53 & 0,15 & 0,57 & 0,19 & 0,70 & 0,19 \\
\hline Total power requirement & $\mathrm{kW}$ & 479,49 & 46,15 & 670,53 & 93,15 & 862,57 & 84,19 & 1054,70 & 102,19 \\
\hline Produced energy & $\mathrm{kW}$ & 433,0 & 0,0 & 607,0 & 0,0 & 780,0 & 0,0 & 953,0 & 0,0 \\
\hline
\end{tabular}

It can be seen that the amount of energy to be consumed is increased proportionally with the growth of the delivery task. While at $10,000 \mathrm{~m}^{3} / \mathrm{h}, 433 \mathrm{~kW}$ of energy can be extracted with a turbo expander, $953 \mathrm{~kW}$ can be produced at $22,000 \mathrm{~m}^{3} / \mathrm{h}$. Energy demand for preheating gas is also increasing proportionally. The energy demand of the gas boiler is almost always at least $99 \%$ of the invested energy requirement, but this is technological use of natural gas 
INVESTIGATION OF PRESSURE REGULATOR REPLACEMENT BY TURBO EXPANDER IN HUNGARIAN GAS TRANSFER STATIONS

Anna Bella Galyas; László Tihanyi; István Szunyog; László Kis

within the gas transmission system, which can be accounted for by a system operator at a significantly lower price. The required pump power does not exceed $1 \mathrm{~kW}$. For the gas flow of $10,000 \mathrm{~m}^{3} / \mathrm{h}$, nearly $520 \mathrm{~kW}$ of heat output is required for the theoretical performance of $433 \mathrm{~kW}$, thus $87 \mathrm{~kW}$ own energy investment is required. In the case of the pressure regulator there is no power generation, $87 \mathrm{~kW}$ of heat is required for the preheating of the gas to maintain the prescribed $0{ }^{\circ} \mathrm{C}$ and 6 bar.

With pressure regulation using a turbo expander, the power requirement for $22,000 \mathrm{~m}^{3} / \mathrm{h}$ is $1,143 \mathrm{~kW}$ due to natural gas preheating and $953 \mathrm{~kW}$ mechanical or slightly lower electrical output is achievable. When the temperature dependence is investigated using the energy balance of the gas transfer stations, it is apparent that as the temperature of the natural gas from the supply line increases, the energy demand of the preheating is reduced. It can also be seen that in case of a given transport capacity, the increase of the gas temperature does not affect the energy produced by the turbo expander. At the same time, if the gas temperature increases, the boiler's power requirement is reduced. While in the case of $10,000 \mathrm{~m}^{3} / \mathrm{h}$, at $4{ }^{\circ} \mathrm{C}$, nearly $520 \mathrm{~kW}$ power demand was required during the preheating of gas, in the case of $12{ }^{\circ} \mathrm{C}$ this value is reduced to $480 \mathrm{~kW}$. However, in both cases $433 \mathrm{~kW}$ can be gained with a turbo expander. While in the former case there is a difference of $87 \mathrm{~kW}$ between the heating circuit and the output power, in the latter case it is only $47 \mathrm{~kW}$. Table 2 summarizes the calculation results for a 55 bar inlet pressure.

Table 2 The amount of produced energy at 55 bar inlet pressure

\begin{tabular}{|c|c|c|c|c|c|c|c|c|c|}
\hline \multirow{2}{*}{$\begin{array}{l}p=55 \mathrm{bar} \\
\mathrm{T}=4^{\circ} \mathrm{C}\end{array}$} & \multirow[t]{2}{*}{ Unit } & \multicolumn{2}{|c|}{$Q=10,000 \mathrm{~m}^{3} / \mathrm{h}$} & \multicolumn{2}{|c|}{$\mathrm{Q}=14,000 \mathrm{~m}^{3} / \mathrm{h}$} & \multicolumn{2}{|c|}{$Q=18,000 \mathrm{~m}^{3} / \mathrm{h}$} & \multicolumn{2}{|c|}{$\mathrm{Q}=22,000 \mathrm{~m}^{3} / \mathrm{h}$} \\
\hline & & Exp. & Valve & Exp. & Valve & Exp. & Valve & Exp. & Valve \\
\hline Heating power & $\mathrm{kW}$ & 595,0 & 114,0 & 832,0 & 160,0 & 1070,0 & 206,0 & 1308,0 & 252,0 \\
\hline Pump power & $\mathrm{kW}$ & 0,53 & 0,15 & 0,62 & 0,19 & 0,71 & 0,26 & 0,80 & 0,30 \\
\hline Total power requirement & $\mathrm{kW}$ & 595,53 & 114,15 & 832,62 & 160,19 & 1070,71 & 206,26 & 1308,80 & 252,30 \\
\hline Produced energy & $\mathrm{kW}$ & 481,0 & 0,0 & 673,0 & 0,0 & 866,0 & 0,0 & 1059,0 & 0,0 \\
\hline $\mathrm{T}=\mathbf{8}^{\circ} \mathrm{C}$ & & Exp. & Valve & Exp. & Valve & Exp. & Valve & Exp. & Valve \\
\hline Heating power & $\mathrm{kW}$ & 573,0 & 93,0 & 803,0 & 130,0 & 1032,0 & 167,0 & 1263,0 & 204,0 \\
\hline Pump power & $\mathrm{kW}$ & 0,53 & 0,15 & 0,62 & 0,19 & 0,71 & 0,26 & 0,80 & 0,30 \\
\hline Total power requi & $\mathrm{kW}$ & 573,53 & 93,15 & 803,62 & 130,19 & 1032,71 & 167,26 & 1262,80 & 204,30 \\
\hline Produced energy & $\mathrm{kW}$ & 481,0 & 0,0 & 673,0 & 0,0 & 866,0 & 0,0 & 1059,0 & 0,0 \\
\hline $\mathrm{T}=12^{\circ} \mathrm{C}$ & & Exp. & Valve & Exp. & Valve & Exp. & Valve & Exp. & Valve \\
\hline Heating power & $\mathrm{kW}$ & 552,0 & 72,0 & 773,0 & 101,0 & 995,0 & 130,0 & 1217,0 & 159,0 \\
\hline Pump power & $\mathrm{kW}$ & 0,53 & 0,15 & 0,62 & 0,19 & 0,70 & 0,26 & 0,80 & 0,30 \\
\hline Total power requirement & $\mathrm{kW}$ & 552,53 & 72,15 & 773,62 & 101,19 & 995,70 & 130,26 & 1217,80 & 159,30 \\
\hline Produced energy & $\mathrm{kW}$ & 481,0 & 0,0 & 673,0 & 0,0 & 866,0 & 0,0 & 1059,0 & 0,0 \\
\hline
\end{tabular}

Compared with the above tested variants, an elevated pressure increased the power required for both the gas preheating and the power produced by the turbo expander.

By comparing the power balance of the $10000 \mathrm{~m}^{3} / \mathrm{h}$ and $4{ }^{\circ} \mathrm{C}$ at 45 bar and 55 bar, it can be seen that a higher power requirement is due to the higher inlet pressure, but the recoverable power by the turbo expander will also increase. This can be explained by the higher amount of cold energy due to the increased pressure. Due to the higher inlet pressure, it is necessary to maintain a higher temperature in the preheating process which requires a higher amount of water due to the pressure build-up to meet the boundary conditions of the outlet point of the gas transfer station.
It can be stated that in the case of higher-temperature natural gas there is a lower pre-heating demand, thus ultimately less power and energy demand for pressure regulation. It can be stated that at higher natural gas temperatures the process of pressure regulation with the turbo expander can be operated more economically.

\subsubsection{Examination of Medium Capacity Gas Transfer Station}

The gas transfer stations in this category are further away from the compressor station and the number of supplied consumers is smaller. The presumed arrival pressure is between 35 and 40 bar, the maximum capacity of the gas transfer station is in the range of 3,000 to 6,000 $\mathrm{m}^{3} / \mathrm{h}$. 
INVESTIGATION OF PRESSURE REGULATOR REPLACEMENT BY TURBO EXPANDER IN HUNGARIAN GAS TRANSFER STATIONS

Anna Bella Galyas; László Tihanyi; István Szunyog; László Kis

Table 3 The amount of produced energy at medium capacity gas transfer station

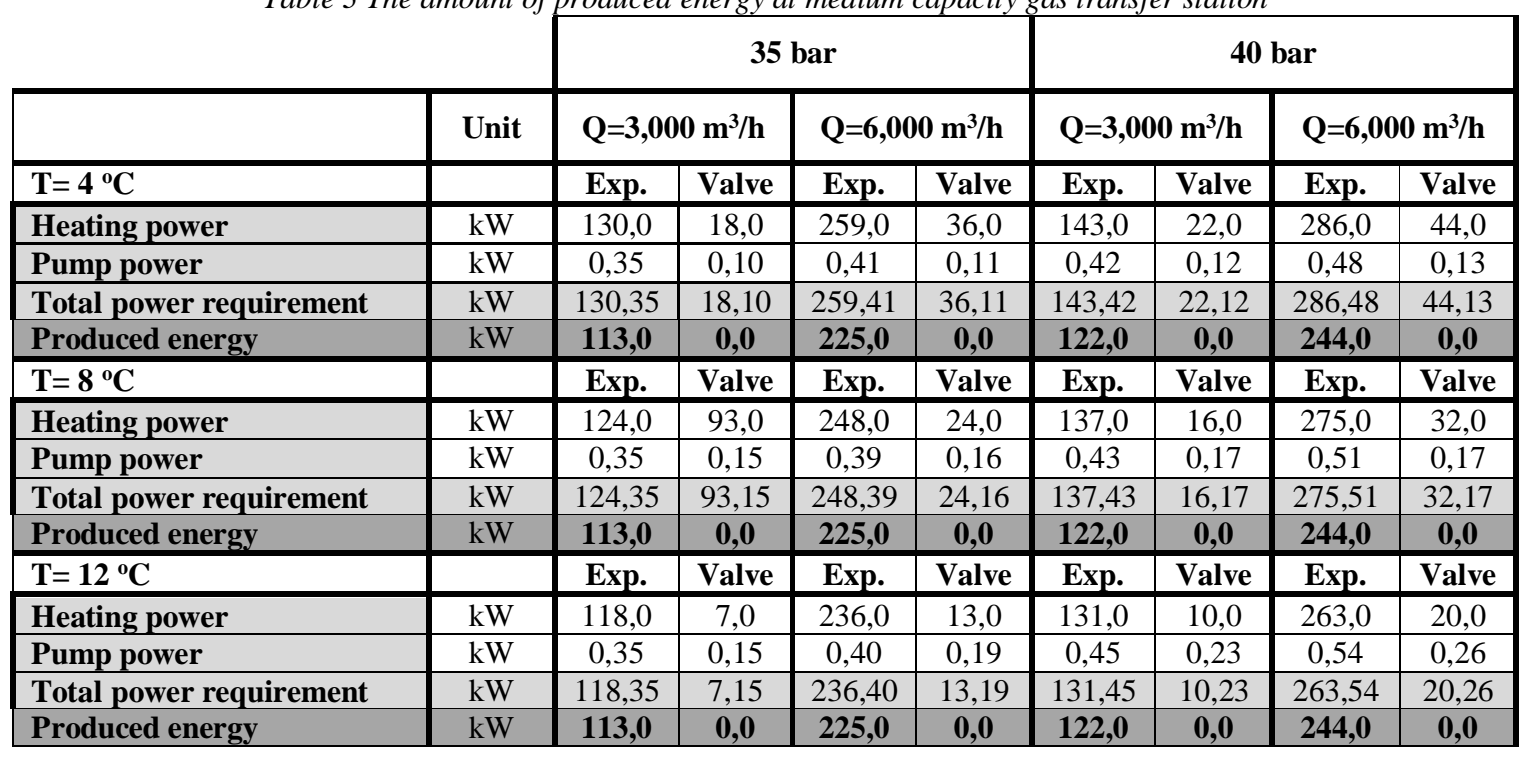

In Table 3, the elements of the energy balance change in the same way as in the case of medium gas flows and pressures as in the case of high pressure capacity stations. In addition to a given natural gas flow rate, the theoretical energy balance is more favourable if the temperature of the arriving natural gas is higher, as this results in a reduction in the demand for gas preheating. Based on the above, it can be said that, if the pressure is higher, the theoretical gain is greater from the process, but more energy is needed. Overall, the change is unfavourable.

\subsubsection{Examination of Small Capacity Gas Transfer Station with Small Inlet Pressure}

If the gas transfer station is far away from the compressor station, the inlet pressure of the station is small, it is in the range of 25 to 30 bar compared to the previous categories. This is accompanied by a small maximum load, assuming a hourly natural gas quantity of 1,000 to 2,000 $\mathrm{m}^{3}$.

Table 4 shows that very little performance values have been reported in each element of the theoretical energy balance compared to the previous two categories.

Table 4 The amount of produced energy at small capacity gas transfer station

\begin{tabular}{|c|c|c|c|c|c|c|c|c|c|}
\hline & \multicolumn{4}{|c|}{25 bar } & \multicolumn{4}{|c|}{30 bar } \\
\hline & \multirow[t]{2}{*}{ Unit } & \multicolumn{2}{|c|}{$\mathrm{Q}=1,000 \mathrm{~m}^{3} / \mathrm{h}$} & \multicolumn{2}{|c|}{$\mathrm{Q}=\mathbf{2 , 0 0 0 \mathrm { m } ^ { 3 } / \mathrm { h }}$} & \multicolumn{2}{|c|}{$\mathrm{Q}=1,000 \mathrm{~m}^{3} / \mathrm{h}$} & \multicolumn{2}{|c|}{ 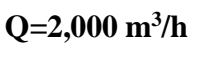 } \\
\hline $\mathrm{T}=4^{\circ} \mathrm{C}$ & & Exp. & Valve & Exp. & Valve & Exp. & Valve & Exp. & Valve \\
\hline Heating power & $\mathrm{kW}$ & 33,0 & 3,5 & 65,0 & 7,0 & 38,0 & 5,0 & 75,0 & 10,0 \\
\hline Pump power & $\mathrm{kW}$ & 0,20 & 0,10 & 0,22 & 0,11 & 0,22 & 0,12 & 0,22 & 0,13 \\
\hline Total power requirement & $\mathrm{kW}$ & 33,20 & 3,10 & 65,22 & 7,11 & 38,22 & 5,12 & 75,22 & 10,13 \\
\hline Produced energy & $\mathrm{kW}$ & 2,20 & 3,10 & 5,22 & 7,11 & 4,22 & 5,12 & 7,22 & 10,13 \\
\hline $\mathrm{T}=8^{\circ} \mathrm{C}$ & & Exp. & Valve & Exp. & Valve & Exp. & Valve & Exp. & Valve \\
\hline Heating power & $\mathrm{kW}$ & 31,0 & 1,5 & 61,0 & 2,5 & 37,0 & 3,0 & 71,0 & 6,0 \\
\hline Pump power & $\mathrm{kW}$ & 0,20 & 0,10 & 0,20 & 0,10 & 0,22 & 0,12 & 0,21 & 0,13 \\
\hline Total power requirement & $\mathrm{kW}$ & 31,20 & 1,60 & 61,20 & 2,60 & 37,22 & 3,12 & 71,21 & 6,13 \\
\hline Produced energy & $\mathbf{k W}$ & 30,0 & $\mathbf{0 , 0}$ & 60,0 & $\mathbf{0 , 0}$ & 34,0 & $\mathbf{0 , 0}$ & 68,0 & $\mathbf{0 , 0}$ \\
\hline $\mathrm{T}=12^{\circ} \mathrm{C}$ & & Exp. & Valve & Exp. & Valve & Exp. & Valve & Exp. & Valve \\
\hline Heating power & $\mathrm{kW}$ & 30,0 & 0,5 & 60,0 & 1,0 & 34,0 & 1,0 & 64,0 & 2,0 \\
\hline Pump power & $\mathrm{kW}$ & 0,20 & 0,10 & 0,20 & 0,08 & 0,21 & 0,11 & 0,20 & 0,12 \\
\hline Total power requirement & $\mathrm{kW}$ & 30,20 & 0,15 & 60,20 & 1,08 & 34,21 & 1,11 & 64,20 & 2,12 \\
\hline Produced energy & $\mathbf{k W}$ & 30,0 & $\mathbf{0 , 0}$ & 60,0 & $\mathbf{0 , 0}$ & 34,0 & $\mathbf{0 , 0}$ & 68,0 & $\mathbf{0 , 0}$ \\
\hline
\end{tabular}


It can be stated, therefore, that in the case of stations with small arriving pressure and small gas flow, the importance of energy production with turbo expander units is negligible. It can be stated that the replacement of the pressure regulating equipment by a turbo expander in gas transfer stations at such conditions cannot be proposed energetically.

Figure 4 shows a summary of the results of the versions presented so far. On the vertical axis, the theoretical performance of the turbo expander unit is presented in the process, expressed in units of $\mathrm{kW}$.

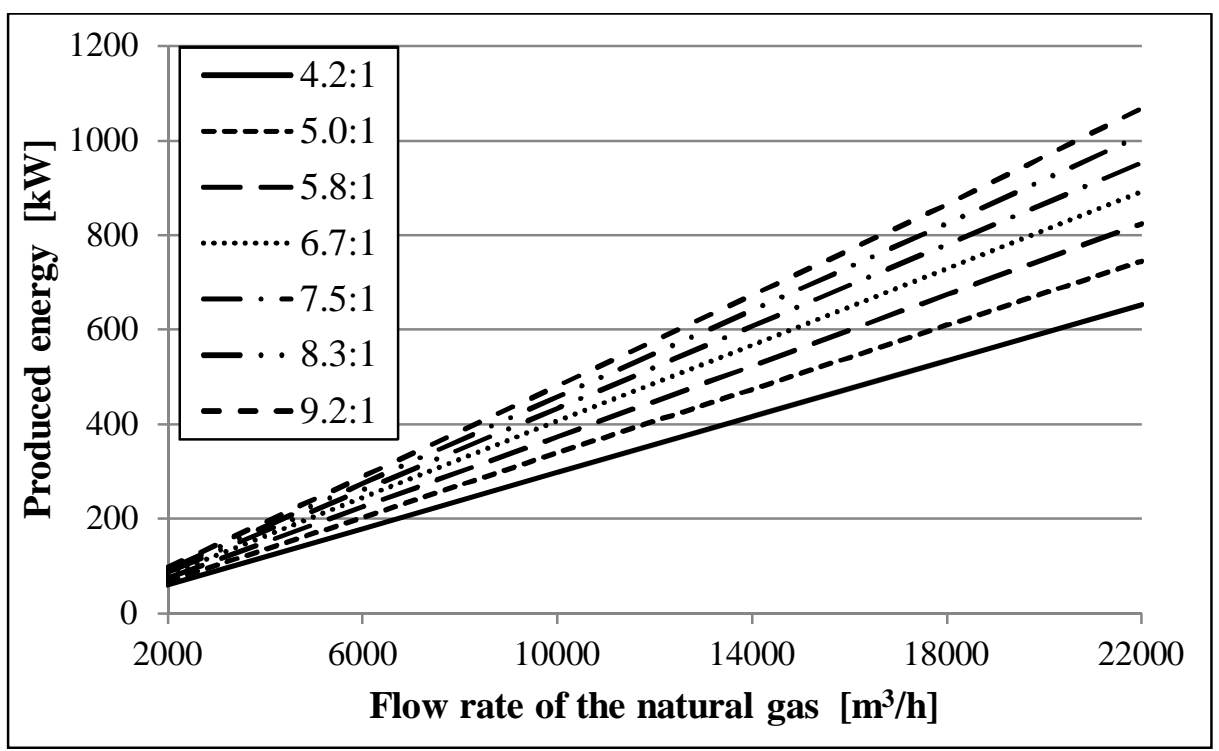

Figure 4 Theoretical production of electricity, depending on the pressure ratio and the amount of natural gas

The horizontal axis shows the maximum gas flow of the gas transfer stations, in $\mathrm{m}^{3} / \mathrm{h}$ unit. Each curve expresses the pressure ratio that can be derived from the inlet pressure of the gas transfer station and from the fixed 6 bar outlet pressure considered as the base parameter. Of course, the pressure reduction process from 25 bar to 6 bar has a ratio of 4.2: 1, a pressure ratio of 5.0: 1 for the process from 30 bar to 6 bar, and thus the maximum 55 bar for which the pressure ratio of 9.2: 1 is given in the figure above.

In Figure 4, only the amount of energy extracted by the turbo expander was depicted, without the power required to preheat the natural gas. Observing the figure, all pressure curves are located at almost a single starting point for a gas transfer station with a load of $2,000 \mathrm{~m}^{3} / \mathrm{h}$. As the maximum flow rate of the gas transfer station increases, the amount of energy that can be produced increases. It can also be observed that at higher pressure ratios, more energy production can be achieved. In the case of a gas transfer station with a maximum capacity of $22,000 \mathrm{~m}^{3} / \mathrm{h}$, higher power generation occurs when the specified end point conditions are $0{ }^{\circ} \mathrm{C}$ and 6 bar achieved by an inlet pressure of 55 bar and not the minimum pressure of 25 bar.

Figure 5 depicts temperature change curves for turbo expander and for conventional pressure control valve, as a function of pressure drop. At the inlet point of the turbo expander, a significantly higher temperature is required to ensure that at the end of the isentropic process the natural gas temperature is above $0{ }^{\circ} \mathrm{C}$. It can be seen from the figure that at a pressure drop of $19 \mathrm{bar}$, in the case of isenthalpic throttle, only a decrease of $10.7{ }^{\circ} \mathrm{C}$ occurs; the isentropic expansion results in a decrease of approximately $74^{\circ} \mathrm{C}$. Obviously, increasing pressure drop is associated with an increasing temperature change. At 49 bar pressure change, in the case of isenthalpic case the temperature difference slightly exceeds $20^{\circ} \mathrm{C}$; in the isentropic $120{ }^{\circ} \mathrm{C}$ is required to meet the $0{ }^{\circ} \mathrm{C}$ criteria. 


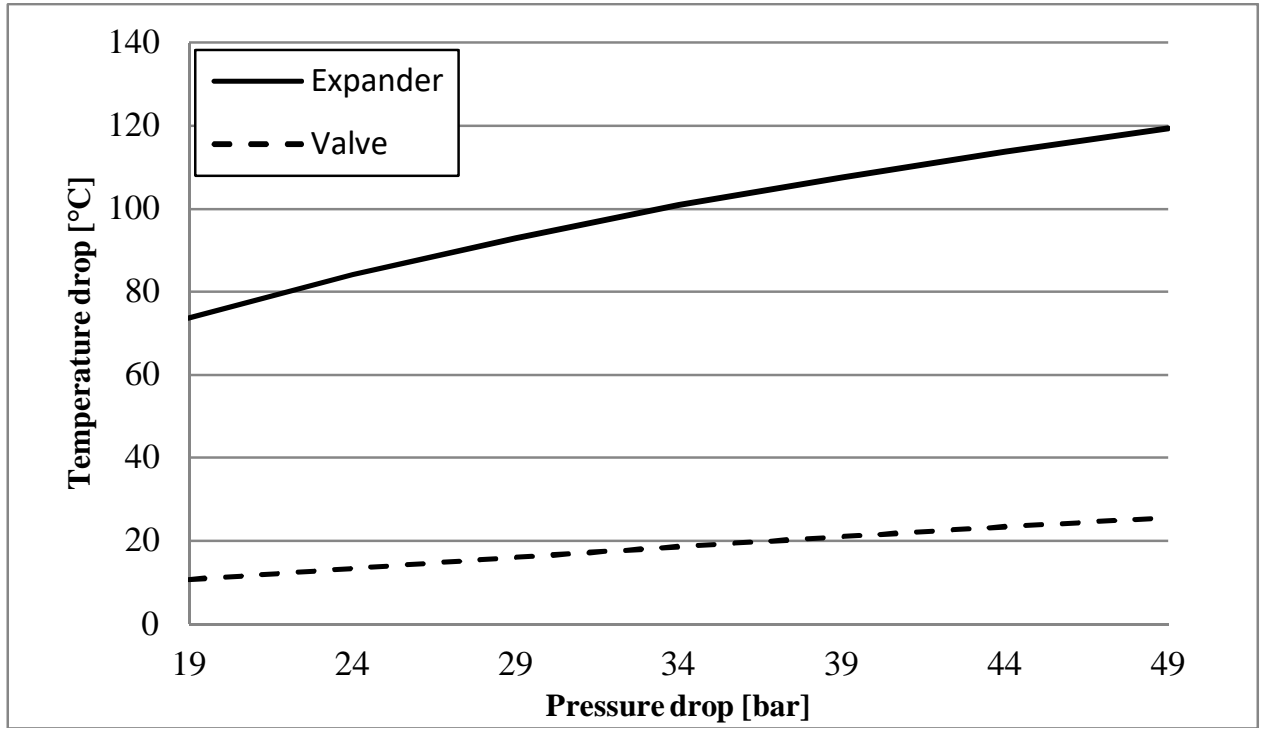

Figure 5 Temperature drop depending on pressure drop

\section{Conclusion}

The replacement of pressure regulators installed at the gas transfer stations with turbo expander has been applied since the 1980s. Using cold energy that can be extracted during the isentropic pressure regulating process, electricity can be generated using a connected generator, which is widely used.

The energy efficiency of the turbo expander installed at the domestic gas transfer stations was investigated, to which the Aspen HYSYS simulation software was used. The fulfilment of the $0{ }^{\circ} \mathrm{C}$ and 6 bar criteria set forth in ÜKSZ was considered to be the basic condition in order to ensure the supply of high-medium distribution network through the gas-transfer station in a regulated framework.

The simulation could be implemented using a model by installing a turbo expander unit on the control branch. On the parallel control line a conventional pressure control valve was used.

It has been found that the replacement of pressure control valves is highly desirable for gas transfer stations with high pressure and high gas flow. In the case of a large $\left(22,000 \mathrm{~m}^{3} / \mathrm{h}\right) \mathrm{gas}$ load, up to $1 \mathrm{MW}$ of theoretical energy can be extracted from the pressure regulating process. In the case of medium and low-arrival pressure and capacity stations, however, there is a lower level of energy production, which is why it is not advisable to install turbo expander.

We have found that turbo expander pressure regulation requires very high temperatures in front of the unit to meet the output side $0{ }^{\circ} \mathrm{C}$ temperature criteria. Therefore, the gas should be heated to a higher temperature than that of the isenthalpic throttle. Thus, the boiler for preheating requires greater power than in the case using a control valve. Since it is a gas boiler, it does not use electricity, but uses natural gas for its own use, which the natural gas transmission system operator can account for at a significantly lower price.

The expansion of the expansion turbines on gas transfer stations is becoming more common in the world, and many examples serve as evidence. More and more projects and studies deal with the topic around the world, as the latency inherent in the process seems to be justified from an energy management point of view.

\section{Acknowledgments}

The described work/article was carried out as part of the „Sustainable Raw Material Management Thematic Network - RING 2017”, EFOP-3.6.2-16-2017-00010 project in the framework of the Széchenyi2020 Program. The realization of this project is supported by the European Union, co-financed by the European Social Fund.

\section{References}

[1] A Framework Strategy for a Resilient Energy Union with a Forward-Looking Climate Change Policy, European Commission, COM(2015) 80 final, 2015.

[2] TIHANYI, L., ZSUGA, J.: Földgázszállító rendszerek tervezése és létesítése, University of Miskolc, ISBN 978-963-661-999-2, 2012. (Original in Hungarian)

[3] TIHANYI, L., CHOVÁN, P.: Gázszállító rendszerek energetikai elemzése, Magyar Energetika, Vol. 22, Issue 4, pp. 40-43, 2015. (Original in Hungarian)

[4] A Magyar Földgázrendszer Üzemi és Kereskedelmi Szabályzata (2015), Available: 


\section{INVESTIGATION OF PRESSURE REGULATOR REPLACEMENT BY TURBO EXPANDER IN HUNGARIAN} GAS TRANSFER STATIONS

Anna Bella Galyas; László Tihanyi; István Szunyog; László Kis

https://fgsz.hu/sites/default/files/dokumentumok/jogsz abalyok/publikalt_torzs_6454-2015_mekh _hat_alapjan.pdf_(Original in Hungarian)

[5] Interstate Natural Gas Association of America Waste Energy Recovery Opportunities for Interstate Natural Gas Pipelines, Available: http://www.ingaa.org/file.as px?id=6210, 2008.

[6] ARDALI, E. K., HEYBATIAN, E.: Energy Regeneration in Natural Gas Pressure Reduction Stations by Use if Gas Turbo Expander; Evaluation of Available Potential in Iran, Argentina, $24^{\text {th }}$ World Gas Conference, 2009.

[7] POZIVIL, J.: Use of Expansion Turbines in Natural Gas Pressure Reduction Stations, Acta Montanistica Slovaca, Vol. 9, Issue 3, pp. 258-260, 2009.

[8] BISIO, G.: Thermodinamic Analysis of the Use of Pressure Exergy of Natural Gas, Energy, Vol. 20, Issue 2, pp. 161-167, 1995.

[9] BLOCH, H., SOARES, C.: Turboexpanders and Process Applications, Gulf Professional, ISBN 978-088415-509-6, 2001.

[10] DELGADO CALIN, G.: Energy Efficiency Projects with Turboexpanders Application to Combined Cycle Power Plants, 20th International Congress on Project Management and Engineering, Cartagena, 2016.

[11] ELSOBKI, M.: Boosting Capacity of Electric Generation through the use of Turbo expanders in Natural Gas Network, Egyptian German High Level
Joint Committee for Renewable Energy, Energy Efficiency and Environmental Protection, Available: http://egyptera.org/Downloads/events/Turboexpander \%20Report,\%2024\%20 Nov.-MSE.pdf, 2013.

[12] FARZANEH-GORD, M., MANZARI, M., MAGRABI, M., HASHEMI, S., EFTEKHARI, H., FAROKHI, A.: Using pressure exergy of natural gas in Bandar-Abbas refinery gas pressure drop station, The second International conference on Modeling, Simulation, And Applied optimization, Abu Dhabi, UAE, 2007.

[13] RAHMAN, M.: Power generation from pressure reduction in the natural gas supply chain in Bangladesh, Journal of Mechanical Engineering, Vol. 41, Issue 2, pp. 89-95, 2010.

[14] RHEUBAN, J.: Turbo expanders, Harnessing the Hidden Potential of Our Natural Gas Distribution System, Available: http://jacobrheuban.com/ 2009/03/09/turboexpanders-harnessing-the-hiddenpotential-of-our-natural-gas-distribution-system/, 2009.

[15] KOWALA, D.: Using the gas pressure potential for electricity generation at Pressure Reduction Stations, GERG Academic Network Event, Brussels, 2007.

\section{Review process}

Single-blind peer review process. 